\title{
Bamboo as a Sustainable Material for Building Construction in Nigeria
}

\author{
AUWALU, Faisal Koko ${ }^{1^{*}}$ DICKSON, Panshak Dakur ${ }^{2}$ \\ 1.College of Civil Engineering and Architecture, Zhejiang Architecture and Urban Planning, Zhejiang \\ University, Hangzhou, Zhejiang 310058, China \\ 2.Nigerian Building and Road Research Institute (NBRRI). Abuja, Nigeria
}

\begin{abstract}
Bamboo as a material for building construction was assessed for its sustainability using data from secondary sources. It is a well-known fact that a sustainable material for building construction must be environmentally friendly, affordable, flexible in usage, and durable, which makes bamboo one because of these characteristics it possesses. Also, due to its rapid growth and adaptability to most climatic conditions as well as its properties and superiority to most rapidly growing plant in Nigeria, bamboo emerges as a sustainable material for building construction in Nigeria. Bamboo has numerous unique advantages like the ability to grow fast with a high yield, environmental friendliness, lightness in weight, and matures quickly for harvesting. Additionally, bamboo can be grown abundantly at a lower cost than other building materials, which makes it more economical. This study, therefore, deals with the main properties and significant uses of bamboo and also identifies some of the challenges faced in the use of bamboo as a sustainable material for building construction. The study concluded that bamboo could be used as a building material for various construction purposes such as foundations, floors, walls and ceilings, doors, and windows, scaffolding, trusses, and roofing. It also suggests the various preservation techniques to be adopted in order to enhance its durability and lifespan for building construction purposes. The study consequently recommended that since bamboo is readily available in Nigeria, it is therefore proposed for use as a sustainable material for building construction. However, the various problems which are associated with the usage of bamboo as a building material such as attack by insects and fungi can be improved with the use of chemical and non-chemical preservative treatments that enhances durability and life span.
\end{abstract}

Keywords: Bamboo, Sustainable, Building Material, Construction, Nigeria

DOI: $10.7176 / \mathrm{CER} / 11-8-03$

Publication date:September $30^{\text {th }} 2019$

\section{Introduction}

Bamboo is a renewable resource that is versatile and characterised by its high strength and low weight, as well as its ability to be readily worked using simple tools. It is generally acknowledged to be one of the most important non-timber forest resources due to the tremendous socio-economic benefits derived from bamboo-based products. With over a 1000 species and classified in roughly 90 genera which grow in diverse climates throughout the world. Most bamboo is harvested from the wild with only about 50 to 100 of the useful species domesticated and cultivated for commercial use around the world (Paglione, 2003). Bamboo is also considered to be the fastestgrowing woody plant in the world with an approximate growth height of 7.5 to $40 \mathrm{~cm}$ a day as stated by Wong (1995), with the world record being in Japan with an approximate growth of $1.2 \mathrm{~m}$ in a day. Bamboo is a woody plant which grows about three times faster than most other species. Commercially significant species of bamboo usually mature in four or five years, after which continuous harvests are possible every subsequent year, for up to 120 years in some species and indefinitely in others. Bamboo cultivation and harvesting serve as a source of livelihood for millions of rural inhabitant in many developing countries, and in particular women and children who do most of the harvesting. Several species of bamboo grow in Sub-Saharan Africa, most notably Nigeria, but their uses have been limited to constructing traditional houses, irrigation systems, handcrafts, fuel, and food. However, Nigeria's abundant bamboo resource is virtually unexploited in any significant way. In the last few years, several researchers and organisations have been promoting its potential as a sustainable material for building construction, but their success is yet to be acknowledged. Today, advocates of bamboo as a building material perceive it as an attractive and sustainable building material for construction use while its antagonists opine that it is unreliable for construction purposes. However, Andreas (2005) believes that construction professionals are only limited not by the material but their knowledge of how the material works.

Aim and Objective

This study aims to assess the potential of bamboo as a sustainable material for building construction in Nigeria.

To achieve this aim, the objectives of the study are as follows:

i.To study the properties of bamboo as a building material.

ii.To examine the sustainability of bamboo as a building material.

iii.To study the challenges of bamboo as a material for building construction.

iv.To propose recommendations that will enhance the use of bamboo as a building material for construction in 
Nigeria.

\section{Availability of Bamboo in Nigeria}

Bamboo is a building material that is readily available in Nigeria but has not been properly utilized as established by various researches (American Bamboo Society, 2002; Anon., 1987 and Cleaver, 1993). The report of Raw Materials Research and Development Council (RMRDC), (2004) described bamboo as a widely available and distributed material for building construction in the Southern and Middle belt regions of Nigeria. According to the report, the distribution of bamboo in Nigeria is associated with the ecological conditions of the rainforest areas having the most abundant rainfall. The distribution pattern indicates that bamboo is particularly adapted to the rainforest belt of Nigeria where it is found in abundance due to the high mean annual rainfall and length of the rainy season. According to Aribisala (1993), the Southern parts of Nigeria has the highest mean annual rainfall, which is more than $1000 \mathrm{~mm}$ as compared to the North-Central zone which has a mean annual rainfall of between $600-1000 \mathrm{~mm}$. The North-Western and the North-Eastern zone of the country has a mean annual rainfall of between $400-600 \mathrm{~mm}$. Taraba State in the North-Western region of Nigeria has a sub-temperate climate which makes available in the state because of this climate (RMRDC, 2004). Bamboo is commonly available in almost all the states of Southern region of Nigeria except for Bayelsa State and Lagos State where the distribution is considered to be relatively low. The states with the abundance of bamboo occurrence are identified to be Abia, Anambra, Akwa Ibom, Cross River, Delta, Edo, Ebonyi, Enugu, Imo, Ogun, Oyo, Osun, Ondo, and Rivers States. Also, the report of RMRDC (2004) indicates that at least ten (10) per cent of the natural vegetation in these states is dominated by bamboo, with the existing bamboo clumps showing substantial gregarious growth that is continuous over large areas. In states like Bayelsa, Benue, Ekiti, Kogi, Kwara, Lagos and Nassarawa States, the distribution of bamboo was observed to be frequent, indicating that between six (6) to nine (9) per cent of the natural vegetation is occupied by bamboo. Several bamboo clumps were also reported in Niger, Plateau and Taraba States as well as within the Federal Capital Territory (FCT). However, there are 12 North-Western and North-Eastern states where the bamboo occurrence is rare. These states include Adamawa, Bauchi, Borno, Gombe, Kano, Kaduna, Katsina, Kebbi, Sokoto, Jigawa, Yobe, and Zamfara State.

\section{Properties of Bamboo}

\subsection{Tensile Strength}

Bamboo has strength properties which are excellent, particularly with regards to the tensile strength (Wakchaure \& Kute, 2012; Moroz et al., 2014). Most strength properties of bamboo depend on the species and the climatic condition in which they grow (Sekhar and Gulati, 1973). The Strength of bamboo varies along with the height of culm. The compressive strength of bamboo increases with its height while bending strength has an opposite trend (Liese, 1986; Espiloy, 1994; Kabir et al., 1991, 1993). An increase in the strength of bamboo is believed to occur between 3 to 4 years, and after that decreases (Espiloy, 1994). The outer zone of bamboo has a highly elastic vascular bundle, which also have high tensile strength while the fibre of bamboo run axially, making it more resistant to tension than compression. The high tensile strength of this bamboo fibres is usually higher than that of steel but has a disadvantage of not being possible to construct connections that can transfer this tensile strength.

\subsection{Shrinking}

Bamboo has a property which makes it shrinks more than timber as it loses its water content. The canes of the bamboo can tear apart at the nodes making it shrink in the cross-section ca. usually between $10-16 \%$, and wall thickness ca. of between 15-17\% (Rehman and Ishaq, 1947). Therefore, when using bamboo as a material for building construction, it is necessary to take precautionary measures aimed at preventing water loss.

\subsection{Anisotropic Properties}

Bamboo is an anisotropic material. The properties of bamboo in the longitudinal direction are entirely different as that of the transversal direction. The longitudinal direction has cellulose fibres that are durable and stiff, whereas the transverse direction has lignin, which is soft and brittle.

\subsection{Compressive Strength}

Bamboo with slimmer tubes has a higher compressive strength value than bamboos with larger tubes as regard to their cross-section. Bamboo with slimmer tubes possesses better material properties because larger tubes of bamboo usually have a disadvantage of having a minor part of the outer skin that is highly resistant to tension. Hence, Compressive strength is affected by the portion of lignin inside the culms and the large portion of cellulose influences buckling and the tensile strength because it represents the building substance of the bamboo fabrics.

\subsection{Elastic Modulus}

The accumulation of highly durable fibres in the outer parts of the bamboo tube wall works positively in connection 
with the elastic modulus like it does for the tension, shear, and bending strength of bamboo. The higher the elastic modulus of bamboo, the higher the quality. This enormous elasticity of bamboo makes it an advantageous material for building construction in areas with very high risks of earthquakes.

\subsection{Fire Resistance}

Bamboo has an excellent fire resistivity due to the high content of silicate acid it possesses. Bamboo which is filled up with water can usually withstand a temperature of $400^{\circ} \mathrm{C}$ while the water cooks inside. It also possesses high moisture content, which is influenced by the age, species as well as the season of harvesting. Although unlike timber, bamboo starts shrinking above the fibre saturation point, the use of Ecology Diversity Synergy technology has remedied this weakness, as EDS treated bamboo is as durable as solid timber for building construction (UNIDO, 2009).

\section{Bamboo as a Sustainable Building Material}

Bamboo is regarded as a sustainable and renewable building construction material which is harvested and replenished sustainably with virtually little or no impact on the environment. Bamboo has an embodied energy which is very low when compared to other construction materials like concrete, steel, and plastic. Bamboo also helps in controlling erosion and flooding as well as controlling the local climates through photosynthesis. Bamboo as a crop is usually cultivated yearly such that only ripped and matured culms are harvested while younger ones are left to grow continuously. After harvesting the matured bamboo, the root system remains unharmed and healthy, which is still ready to yield more shoots, as is in the case of grass. Bamboos are also be regarded as a biodegradable material because its products can be incinerated or digested in sewage. Bamboo, as a building material, possesses high flexibility, strength, and versatility. This favourable characteristics of bamboos make it a suitable building material for practically every part of a building (i.e., foundation, flooring, walls, and roofs) when treated and appropriately used. It also has different use within the building construction industry due to its favourable advantages of easy availability, low cost, and high strength. It can be used to replace conventional and relatively scarce materials such as mild steel and galvanised steel mesh, or various fibres like asbestos in reinforcing cementitious materials. Bamboo is also light in weight but yet a sturdy building material which is usually used for building construction after treatment against fungi and insect infestation. It has the property of a hardwood, which is both light and exceptionally tough. Bamboo structures are usually lightweight, flexible, durable, and have some form of resistance against natural disasters like earthquakes. Bamboos also have the economic advantage of being among the cheapest building materials in addition to other technical advantages of use as a sustainable construction material. Other significant advantages of bamboo as a sustainable building construction material includes prefabrication, easy assembly, and easy replacement of structural parts. Its elements can be easily dismantled and reused, making it a sustainable building material. Bamboos are also used for fences, bridges, and scaffolding. They can be used to reinforce cement concrete flexural and compression members, as well as soil-cement elements. As the case of other vegetable fibres, bamboo fibre could also be used as a substitute for steel reinforcing rods in concrete construction to reinforce cement concretes and mortars. The process is such that meshes made of bamboo splints are used to reinforce cement mortar and obtain thin, fibre-cement-like material.

\subsection{Uses of Bamboo as a Building Material}

Sakaray et al. (2012) and Salzer et al. (2016) has ascribed the use of bamboo for building construction to be diverse, but presently, only a part of temporary structures or buildings in rural and urban areas utilise the use of bamboo for construction in Nigeria. This use does not exploit the full potential of bamboo as a sustainable building material. Hence, other significant uses of bamboo that can be explored in the building construction industry include;

\section{i.Foundations}

The use of bamboo has been limited for the foundation purpose mainly because bamboo deteriorates and decay quickly when in contact with the damp ground. However, despite this disadvantage of deterioration, the use of bamboos for foundation or supporting posts in buildings is possible when treated with some effective preservatives and built on raised platforms. The different construction processes of bamboo foundations include:

a)Bamboo in direct contact with the ground: Bamboos are placed on either the ground surface or buried to the ground. Bamboo with nodes that are closely spaced having large diameters and thick sections are used to achieve the best strength and stability. In the absence of this, smaller sections of bamboos can be tied together and preservatives applied to reduce the process of deterioration that usually occurs between 6 to 24 months.

b)Bamboo on concrete footings or rocks: The stiffest and largest sections of bamboos are used for bearings and are placed on footings of either rock or preformed concrete without direct contact with the ground.

c)Bamboo integrated into concrete footings: The poles of bamboo are directly placed into concrete footing which can take the form of a single post or strip footings.

d)Composite bamboo/concrete columns: A bamboo with a post that is integral and durable is achievable through the use of a concrete extension to the bamboo by using a plastic tube with the same diameter of the bamboo. 
e)Bamboo piles: Bamboo piles are used to reduce settlements of building and stabilise soft soils. This is done through the use of bamboo poles that are split into sections and treated by filling them with coconut coir strands wrapped with jute and tied with wire. Sandy materials are used to cover the area after installation of the piles.

ii.Floors

Bamboo can be used as a building material for flooring due to its wear and tear resistance as well as the resilience properties it possesses. The floor covering is done using bamboo boards, mats, etc. employing wire to the frame. The various construction processes of bamboo flooring include:

a)Small bamboo culms: Bamboo culms are directly tied and nailed together.

b)Split bamboo: Bamboo culms are spitted into strips of several centimetres wide along their length

c) Flattened bamboo: They are produced by splitting bamboo culms and removing the diaphragms, then rolling and flattening the bamboo culms so that the resulting board is laid and fixed by nailing or tying them across the joists. After that, they are screeded with cement mortar to make it easy to clean.

d) Bamboo mats: Thin strips of bamboo which vary in size between 5-6mm or $10-15 \mathrm{~mm}$ and thickness between $0.6-1.2 \mathrm{~mm}$ are woven into mats of different sizes according to construction demand and specification.

e)Bamboo plastic composites: It is an innovative bamboo flooring technology which combines bamboo fibre and plastic as a core material for flooring. It has the advantage of higher water resistivity and dimensional stability than other types of bamboo floorings.

iii. Walls and Partitions

The most common use of bamboo for building construction is for the walls and partitions. Bamboo as a building element is used for columns and beams, which generally constitute the structural framework. They are used to carry the self-weight of building and the imposed loads exerted by the building occupants. An infill between framing members is necessary to protect the wall against rain, wind, and also to offer privacy. The infill in-wall aims to provide in-plane bracing and ensure the overall stability of the overall structure when subjected to horizontal forces.

iv.Doors and windows

Bamboo is also used for doors and windows in buildings. The use of bamboo frames usually replaces the conventional timber frames often used for doors. Bamboo mat shutters are then fixed to the bamboo frame to serve as the door when hinged to the wall. Also, Small bamboo frame can be used to serve as windows when hinged to the top of a wall.

v.Scaffolding

The use of bamboo has for scaffolding has been in existence for centuries in Asian countries like China and Hong Kong and, despite competition with many metal-scaffolding systems, it remains one of the most preferred systems $(\mathrm{Fu}, 1993)$. Also, due to the low construction cost of bamboo and its high adaptability, it can be constructed any layout to follow various irregular architectural features of a building within a relatively short period (Chung et al., 2003). They are used in construction sites in Nigeria to provide temporary access, working platforms for site workers and supervisory staff, and to prevent construction debris from falling onto passers-by. They are either used as Single Layered Bamboo Scaffolds (SLBS) for light work or a Double Layered Bamboo Scaffolds (DLBS) for heavy work. Therefore for Bamboo scaffolding like any other, scaffolding must be laterally stable and must possess integrity.

vi.Trusses

One prominent use of bamboo for building construction is the fabrication of roof trusses. Bamboo has a high strength/weight ratio, which makes it an excellent material for roof framing. Achieving any span of truss is possible with bamboo because of its lightweight property alongside its strength and stiffness. The use of bamboo for trusses also results in considerable savings due to the non-use of heavy lifting equipment.

vii.Roofing

The roof of buildings serves as protection against weather of varying conditions including sun, rain, and wind, and also functions as a shelter for the usable space underneath the roof canopy. The roof should be able to withstand the tremendous forces generated by wind and roof coverings. This makes bamboo a suitable roofing material because of its lightweight and durability. The structure of the bamboo roof can be made of bamboo trusses, rafters, and purlins.

Other uses of bamboo for building construction include:

i.Disaster Mitigation

The lightness and availability of bamboo abundantly as well as the possibility of using bamboo to construct shelters from modular units lead to its use for post-disaster shelter construction. An example is a project by the UNHCR in which temporary shelters are fabricated from A-shaped bamboo frames and supported with horizontal members at the apex and mid-height of the A-shaped frame. A waterproof sheet is then used as draping over this frame for covering.

ii.Bridges

Bamboo materials are also used for the construction of bridges. The bamboo used for such construction purposes 
requires specific constructional techniques, which limit vibration, bending, and twisting due to its property of being much more elastic than solid timber. Such bridges, when constructed with bamboo, are usually covered to reduce their exposure to severe weather conditions. According to Jayaneti and Follet (1998), the various bamboo bridges construction consist of:

a.Footbridges: They are simple bamboo cross-braced frames with the walkway formed at the crutch. Bamboo lashings bind the culms of diameter between 50 to $75 \mathrm{~mm}$. These bridges are suitable for rivers with sandy or muddy base where the height above bed does not exceed five (5) meters. A typical crossing of the bridge might be as long as $20 \mathrm{~m}$.

b.Handcart Bridge: The construction of this bridge is more elaborate, having abutments and pilings. These abutments are formed from pairs of culms of bamboo that are staked to the ground while the bridge assembling is stabilised by horizontal culms which form the pile cap and diagonal braces. Three longitudinal bamboo beams of $100 \mathrm{~mm}$ diameter which are lashed to the caps and tied together at the centre of each bay with a cross-member are used to form the roadway.

\subsection{Challenges to the Use of Bamboo as a Material for Building Construction \\ i.Structure}

The abundantly available bamboo within Nigeria tends not to be very straight, having inconsistent diameters, culm thickness, and showing marked tapering. These structural features serve as a challenge to the utilisation of bamboo for building construction in Nigeria.

ii.Insect and Fungi Attack

Another problem associated with the use of bamboo for building construction is the attack by insect and fungi. Insect attack in bamboo usually occurs through the relatively softer tissues which are within the inside cavity wall and at the budding points in the nodes while fungi attack is severe when bamboo is exposed to damp conditions. According to Jayanetti and Follet (1998), various preservation methods exist for overcoming these attacks. They include various types like the sophisticated modified Boucherie process, through immersion in a boric acid/borax mixture in water, injection, and painting with creosote, to hanging in a flowing stream immediately after harvesting for at least a week to wash out sugary ingredients. Traditional preservation methods also exist, which includes curing, smoking, and lime-washing.

\subsection{Remedies to the Challenges of Bamboo as a Building Material}

Bamboo usually has low natural durability against insect and fungi attacks often between 1 to 3 years. Therefore, preservation and treatment of bamboo are necessary to achieve the required natural durability and lifespan. The treatment of bamboo is usually challenging in dry conditions when using the common preservatives due to the impermeability of its outer and inner membranes to liquids. Hence, the preservation of bamboo is best done in green conditions through chemical treatments. These chemicals are usually used to protect the bamboo against attack by mould, beetles and also prevent the bamboo from changing its nature due to climatic conditions. According to Schroder (2012), the various chemical preservatives used for the treatment of bamboo include the non-fixed preservatives and the preservatives of the fixing type.

i.Non-fixed preservatives

The non-fixed preservative involves the use of boron salts, which are added to the water in which the bamboo is to be soaked. After soaking the bamboo, the water evaporates while the bamboo retains the salt. This salt helps in preventing the appearance of mould, fungi, and termites. Brown and boric acid are one of the most commonly used non-fixed preservatives for bamboo due to its environmentally friendliness and effectiveness. It is also flame retardant and does not contain any hazardous composition.

ii.Preservatives of the fixing type

This type of chemical preservation of bamboo involves the use of a various mixture of different chemicals in a quantitative ratio which interacts with each other and becomes chemically fixed. The various mixtures of these chemicals include Copper-Chromium-Arsenic (CCA), Copper-Chrome-Boron (CCB), Zinc-Chrome, Creosote, Light Organic Solvent-based Preservatives (LOSP), Trichlorophenol (TCP), Copper/Zinc soaps. All these are chemical mixtures that are used to protect the bamboo against various attack by insects and fungi.

\section{Conclusion}

Sustainable building materials are those building materials that are environmentally friendly, readily available, durable, maintainable, and versatile in usage. Bamboo, as a building material, possesses all these qualities and performs better when compared with other commonly used building materials in Nigeria. Therefore, the use of bamboo as a sustainable building material in Nigeria is highly encouraged due to its environmental sustainability, physical and aesthetic qualities, workability, and flexibility of space arrangement, its dry construction, and comparative cost-effectiveness. These properties make it a sustainable building material, which can be used for various construction purposes like foundations, floors, walls and partitions, doors and windows, scaffolding, 
trusses, roofing, as well as other purposes like disaster mitigation and bridge construction. The guiding factor in selecting the appropriate bamboo for a specific construction work includes the detailed knowledge of the functions of the structural unit as well as the specific properties of bamboo with regards to the structural unit and the rate of loading. Adequate information on the magnitude of the load and the duration of the load to be applied should be ascertained in order to develop an informed decision on the appropriate bamboo to be used. Also, appropriate technical knowledge of bamboo, its properties as well as its preservation and treatment techniques is necessary for its use as a sustainable building material for construction. Hence, in order to avoid attacks by insects and fungi, biodegradation, and possible failure and collapse of bamboo structures. It is necessary to subject bamboo to either chemical or non-chemical treatments. These may be in the form of non-fixed preservatives or preservatives of the fixing type which are applied to the bamboo to reduce instances of attack from insects and fungi as well as the distortion of the structural member in service. This subsequently increases the natural durability and lifespan of the bamboo.

\section{References}

American Bamboo Society (2002). Bamboo as a Raw Material.

Andreas, F. (2005). “Architectural forms of massive timber structural forms and system”, Doctoral thesis presented at the Lulca University of Technology Sweden. Page 5- 27. External Scientific Publication.

Anon (1987). The New Encyclopedia Britannica (Macropaedia), Vol. 19, Encyclopaedia Britannia Inc., Chicago. p. 999.

Aribisala, A. O. (1993). "Raw Materials Revolution and Impact on Industrialization in Nigeria". Mednet Publications Ltd. ISBN 978-024-000-4.

Bamboo as a building material, http://www.bambus.com/new/eng/reports/ buildingmaterial/buildingmaterial.html (accessed January 2018).

Chung, K.F.; Chan, S.L.; Ye, W.K., (2002). "Mechanical Properties and Engineering Data of Structural Bamboo". Proceedings of International Seminar on Bamboo Scaffolds in Building Construction, Hong Kong. INBAR, pp: $3-13$.

Chung, K.F., Siu, Y.C. (2002). "Bamboo Scaffoldings in Building Construction - Erection of Bamboo Scaffolds". Hong Kong Polytechnic University/INBAR Publication.

Cleaver, K. (1993). The Population, Environment, and Agriculture. Nexus in Sub-Saharan Africa J.P. Srivastava, H. Akderman (Eds.), Agriculture and environment challenges. Proceedings of the 13th Agricultural sector symposium, The World Bank, Washington D.C.

Espiloy, Z.B. (1994). Effect of age on the physio mechanical properties of some Philippine bamboo. In Bamboo in Asia and the Pacific. Proceedings of the 4th International Bamboo Workshop, Chiangmai, Thailand, 2730 November 1991. International Development Research Center, Ottawa, Canada; Forestry Research Support Programme for Asia and the Pacific, Bangkok, Thailand. Pp. 180-182.

Fu, W.Y. (1993). "Bamboo Scaffolding in Hong Kong”, The Structural Engineer, Vol.71 (11), 202-204.

Jayanetti, D.L.; Follet, P.R., (1998). Bamboo in Construction. INBAR Technical Report No.16. Trada, U.K. pp: 120.

Kabir, M.F.; Bhattacharjee, D.K.; Sattar, M.A. (1991). "Physical and mechanical properties of four bamboo species", Bangladesh Journal of Forest Science, 20(1 \& 2), 31-36.

Kabir, M.F.; Bhattacharjee, D.K.; Sattar, M.A. (1993). "Effect of age and height on strength properties of Dendrocalamus longispaths", Bamboo Information Centre India Bulletin 3(1), 11-15.

Liese, W. (1986). Characterization and utilization of bamboo. In Higuchi, T. Ed. Bamboo production and utilization. Proceedings of the Congress Group 5.04, production and utilization of bamboo and related species, XVIII IUFRO World Congress Ljubljana, Yugoslavia, 7-21 September 1986. Kyoto University, Kyoto, Japan.

Liese, W., (1992). The structure of bamboo in relation to its properties and utilization. In Zhu.

Moroz, J. G., Lissel, S. L., \& Hagel, M. D. (2014). "Performance of bamboo reinforced concrete masonry shear walls", Construction and Building $\quad$ Materials, $\quad$ 61, https://doi.org/10.1016/j.conbuildmat.2014.02.006.

Paglione, J.P.F. (2003). Sustainable biomass production utilising bamboo as an alternative renewable non-wood resource. www.bamboocentral.org/whybamboo.html.

Raw Materials Research and Development Council (2004). Bamboo Production and Utilisation in Nigeria. RMRDC Publications.

Rehman, M.A.; Ishaq, S.M. (1947). "Seasoning and shrinkage of bamboo". Indian Forest Record, 4(21), 1-22.

Sakaray, H., Togati, N. V. K., \& Reddy, I. R. (2012). "Investigation on properties of bamboo as reinforcing material in concrete", International Journal of Engineering Research and Application, 2, 77-83.

Salzer, C., Wallbaum, H., Lopez, L. F., \& Kouyoumji, J. L. (2016). "Sustainability of Social Housing in Asia: A Holistic Multi-Perspective Development Process for Bamboo-Based Construction in the Philippines", Sustainability, 8(2), 151. https://doi.org/10.3390/su8020151. 
Schroder, S. (2012). Chemical Bamboo Preservation. Retrieved June 23, 2019, from https://www.guaduabamboo.com/preservation/chemical-bamboo-preservation.

Sekhar, A.C.and Gulati, A.S. (1973). "Note on the physical and mechanical properties Dendrocalamus strictus from different localities", Van Vigyan, 11(314), 17-22.

United Nations Industrial Development Organization (2009). Bamboo: An untapped and amazing Resource. Retrieved. March 18, 2018.

United Nations Human Settlement Program. (2007). "Situation Analysis of Informal Settlements in Addis Ababa", Nairobi: UN-HABITAT.

Wakchaure, M. R., \& Kute, S. Y. (2012). "Effect of moisture content on physical and mechanical properties of bamboo", Asian Journal of Civil Engineering (Building and Housing), 13(6), 753-763.

Wikipedia. "General Information on Bamboo" http://en.wikipedia.org/wiki/Bamboo. (Accessed 5th March 2018).

Wong, K.M. (1995). The bamboos of Peninsular Malaysia. Forest Research Institute Malaysia (FRIM) in collaboration with Forest Research Center, Forestry Department, Sabah, Malaysia. Malayan Forest Records, No. 41. 